Fikrah: Jurnal Ilmu Aqidah dan Studi Keagamaan

issn 2354-6147 eissn 2476-9649

Tersedia online di: journal.stainkudus.ac.id/index.php/Fikrah

DOI: http://dx.doi.org/10.21043/fikrah.v4i2.1770

\title{
Perubahan Paradigma Beragama (Analisis Perubahan Pemikiran Keagamaan Masyarakat Desa Jepang Mejobo Kudus)
}

\author{
Mas'udi \\ STAIN Kudus, Indonesia \\ masudi@stainkudus.ac.id
}

\begin{abstract}
Abstrak
Artikel ini bertujuan untuk mengamati dinamika keberagamaan yang berjalan di tengah-tengah kehidupan masyarakat Desa Jepang Mejobo Kudus, yang terfokus mengkaji perubahan paradigma masyarakat tentang agama. Berpijak kepada dinamika kehidupan masyarakat yang tergolong abangan, beragama di antara mereka masih tampak mengadaptasi dengan kegiatan kebudayaan yang cenderung ambigu dalam hukum agama. Hal ini bisa dijelaskan seperti menyabung ayam, minuman keras, dan berjudi. Namun, di antara aktivitas ambigu dalam pandangan agama tersebut, masyarakat juga aktif melaksanakan kirim doa kepada para leluhur yang sudah meninggal (hajatan) atau membaca silsilah Syaikh Abdul Qodir al-Jailani (manaqiban). Kehidupan beragama masyarakat Desa Jepang Mejobo Kudus menampakkan adanya perubahan pola keberagamaan. Dimulai dari masifnya kondisi masyarakat yang tergolong abangan, mereka mulai beralih untuk aktif mengisi waktu-waktu luang mereka guna beribadah menjalankan perintah-perintah agama. Aktivitas kebudayaan yang masih banyak dijumpai, seperti menyabung ayam, meminum-minuman keras, dan berjudi, hal tersebut mulai terkikis dengan kegiatan mereka untuk memenuhi tuntutan agama.
\end{abstract}

Kata Kunci: Beragama, keberagamaan, kebudayaan, masyarakat, perubahan 


\begin{abstract}
This article aims at observing the dynamics of diversity that runs in the middle of the Jepang community life, which examines the paradigm shift of public focusing on religion. Based on the dynamics of community life pertaining abangan, religious life among them seem to adapt to the cultural activities tend to be ambiguous in the law. This can be explained as risking chicken, liquor, and gambling. However, among the ambiguous activities in the view of the religion, society is also actively engaged in sending prayers to the departed ancestors (celebration) or reading the genealogy of Sheikh Abdul Qadir al-Jilani (manaqiban). Jepang Village community in religious life of Mejobo Kudus shows any change in the pattern of diversity. Starting from massive societal conditions that pertained abangan, they began to move to actively fill their spare time in order to execute commands worship of religion. Culture activities that are more prevalent, such as risking chicken, liquor-drinking, and gambling, it is eroded by their activities to meet the demands of religion.
\end{abstract}

Keywords: Religion, Religious Activity, Culture, Community, Change

\title{
Pendahuluan
}

Kehadiran agama dalam kehidupan masyarakat merupakan pedoman berharga bagi perjalanan kehidupan mereka. Masyarakat dengan keyakinannya atas suatu agama akan dihantarkan kepada kesadaran bahwa orientasi kehidupannya akan menjadi terarah seiring dengan orientasi dasar dari hakikat agama yang diyakini. Agama akan memberikan ruang komunikasi efektif di antara manusia dengan penciptanya. Kesadaran komunikasi antara manusia dengan penciptanya akan seutuhnya terwujud ketika manusia menyadari arti penting dari agama yang hadir di tengah-tengah kehidupan mereka.

Dalam pertumbuhan agama itu sendiri eksistensinya seringkali menjumpai hal-hal yang bernilai kompleks sehingga menuntut pemaknaan yang terarah agar tidak terjadi kesalahan persepsi. Pada pangkalan inilah, Permata (2000, hal. 14) menjelaskan sifat agama sebagai objek kajian, di dalam dirinya sendiri, merupakan sumber dari segala kerumitan usaha studi terhadapnya. Hingga saat ini, belum pernah terjadi kesepakatan di kalangan para pengkaji mengenai batasan agama di mana pangkal dan di mana ujungnya. Agama muncul sebagai fenomena yang kompleks dan cair, tidak gampang untuk dirumuskan. Ia meresap ke dalam setiap wilayah kehidupan manusia, sehingga kajian terhadap agama selalu akan berhimpitan dengan kajian-kajian bidang lain.

Perspektif yang disampaikan oleh Permata di atas memberikan ruang komunikasi intensif dalam rangka memaknai secara benar eksistensi agama. 
Fenomena agama yang muncul di tengah-tengah kehidupan masyarakat dapat didekati dengan baik bersandar kepada komposisi dari nilai umum agama yang hadir di tengah-tengah kehidupan masyarakat. Dalam kerangka inilah, fenomenologi sebagai salah salah satu kerangka pendekatan dalam studi agama penting dihadirkan guna menjelaskan secara terbuka hakikat agama. Sebagaimana dijelaskan oleh Martin (2011, hal. 10) fenomenologi sangat membutuhkan pendekatan terbuka dan empatik untuk memahami fenomena keagamaan. Salah satu kecenderungan penting historiografi abad ke-19 adalah distingsi yang dibuat Wilhelm Dilthey (1833-1911) dan tokoh lainnya antara ilmu alam dan ilmu alam dan studi budaya (Geisteswissenschaften). Dalam studi budaya atau studi manusia sebagai objeknya adalah seluruh perbuatan dan tindakan manusia yang secara historis melibatkan bentuk-bentuk ekspresi artistik, intelektual, sosial, ekonomi, agama, politik (dan ilmiah). Dari studi manusia sekaligus studi fenomenologi, pemahaman tentang budaya menghendaki pengetahuan lus termasuk psikologi, sejarah, ekonomi, filologi, kritik sastra - pendeknya, semua disiplin yang mengkaji manusia, aktivitas intelektual dan sosialnya. Komponen metodologis terpenting dalam historiografi Dilthey adalah das Verstehen, suatu istilah teknis yang berarti pemahaman tentang gagasan, intensi, dan perasaan orang/masyarakat melalui manifestasi-manifestasi empirik dalam kebudayaan. Metode Verstehen mengandaikan bahwa manusia di seluruh masyarakat dan lingkungan sejarah mengalami kehidupan sebagai bermakna dan mereka mengungkapkan makna ini dalam pola-pola yang dapat dilihat sehingga dapat dianalisis dan dipahami.

Metode Verstehen sebagai usaha memahami makna dapat secara korelatif dihadirkan dalam rangka mengungkapkan makna dasar agama dalam kehidupan masyarakat. Pada kerangka ini, Ahmad Norma Permata mengutip definisi agama sebagai landasan untuk mengerti korelasi aktivitas agama itu sendiri dalam kehidupan masyarakat. Definisi masyhur agama sebagaimana dinukil oleh Permata (2000, hal. 14) adalah pernyataan E.B. Taylor yang merumuskan agama sebagai 'Kepercayaan terhadap wujud spiritual, definisi Allan Menzies, yang emnganggap agama sebagai 'Penyembahan terhadap kekuatan yang lebih tinggi karena adanya yang membutuhkan, atau George Galloway yang merumuskannya sebagai 'Keyakinan manusia kepada sebuah kekuatan yang melampaui dirinya, ke mana ia mencari pemuasan kebutuhan emosional dan mendapatkan ketenangan hidup yang diskpresikan dalam bentuk penyembahan dan pengabdian'.

Berpijak kepada beberapa definisi tentang agama sebagaimana dijelaskan oleh beberapa ahli di atas menunjukkan makna dasar agama sebagai entitas yang akan senantiasa mengkorelasikan eksistensinya terhadap kehidupan keagamaan dan keberagamaan masyarakat. Untuk itulah, demi menganalisis secara seksama atas manifestasi agama dalam kehidupan masyarakat penting untuk menggarisbawahi simpulan dasar pendekatan dalam studi agama sebagaimana dijelaskan oleh Abdurrahman Mas'ud. Dalam simpulan dasar ini, Mas'ud (2004, hal. 48) menjelaskan penting untuk mendudukkan keberadaan agama dalam kerangka kebenaran ilmiah. Kebenaran ilmiah (the truth) memiliki beberapa kriteria yang di antaranya 
adalah; pertama, harus memenuhi teori koherensi atau logically consistent, berpikir secara runtut, yakni pernyataan-pernyataan sebelumnya. Kriteria kedua adalah korespondensi dengan tokohnya Betrand Russel (1872-1970) yang mengatakan "It is better to be clearly wrong than vaguely right" (lebih baik salah tapi jelas, daripada benar tetapi samar-samar). Bagi teori ini, kebenaran terjadi ketika materi pengetahuan yang dikandung pernyataan itu berhubungan (berkoresponden) dengan obyek yang dituju oleh pernyataan tersebut. Yang ketiga adalah kebenaran pragmatis yang dicetuskan oleh Charles S. Pierce (1839-1914). Teori ketiga ini dikembangkan oleh para filsuf Amerika Serikat di antaranya adalah William James (1842-1910), John Dewey (1859-1952), dan sebagainya. Kebenaran di sini diukur apakah satu pernyataan bersifat fungsional dalam kehidupan praktis. Kegunaan praktis dalam kehidupan manusia adalah inti dari teori ini. Kaum pragmatis percaya kepada agama karena agama bersifat fungsional dalam memberikan pegangan moral dan solidaritas sosial. Kaum ini juga percaya pada demokrasi dipandang fungsional dalam menemukan konsensus masyarakat (Mas'ud, 2004, hal. 48).

Tesis yang disampaikan oleh Mas'ud dengan gubahannya atas beberapa perspektif yang disampaikan oleh para ahli tentang manifestasi kebenaran dalam agama menjelaskan bahwa agama dalam faktanya akan menjadi beriringan dengan fenomena kehidupan realistik masyarakat. Pada kerangka dasar inilah dan berpijak kepada beberapa perspektif dasar keagamaan sebagaimana dijelaskan oleh para ahli di atas dapat diungkapkan bahwa fenomena keagamaan dalam kehidupan sosial kemasyarakatan akan senantiasa berkorespondensi terhadap dinamika sosial yang berkembang di sekitarnya. Hal ini bisa dijadikan satu pijakan dasar bahwa hakikat agama yang berkembang di tengah-tengah kehidupan masyarakat Desa Jepang Kecamatan Mejobo Kabupaten Kudus fakta dasar yang bisa disinergikan dengan landasan pemikiran tersebut.

Dalam pertumbuhan penduduknya, Desa Jepang Kecamatan Mejobo Kabupaten Kudus merupakan wilayah dengan tingkat populasi yang padat. Sebagaimana dalam catatan laporan desa, masyarakat Desa Jepang memiliki populasi sejumlah sepuluh ribu jiwa. Jumlah ini terbagi ke dalam beberapa aspek kehidupan sosial dan latar belakang pendidikan. Sumber ekonomi masyarakat Desa Jepang yang beraneka ragam juga menjadi sebab konstruktif keagamaan yang berkembang di tengah-tengah kehidupan mereka. Menjadi buruh pabrik rokok di sekitar kawasan Kota Kudus dan beberapa pabrik lain seperti Pusaka Raya. Sebagian dari mereka juga bekerja pada sektor pertanian dan pembuatan batu bata. Adapun pekerjaan umum yang bisa disaksikan pada kehidupan masyarakat Desa Jepang adalah pembuatan kerajinan tangan dari anyaman bambu. Tidaklah mengherankan, pada pelaksanaan Seremonial Rabu Wekasan di Tahun 2015 mereka mengusung semangat Desa Jepang sebagai desa tirai bambu. Sebuah ikonitas wilayah yang disandarkan kepada negeri Cina yng lebih terkenal dengan negeri Tirai Bambu. Hal itu juga tidak bisa dilepaskan dari usaha besar masyarakat Desa Jepang untuk menghidupkan perekonomian mereka dari hasil anyam bambu. 
Sebagai catatan penting dari rumusan latar belakang PKM (Pengabdian Kepada Masyarakat) ini, Desa Jepang memiliki keunikan tersendiri dalam formulasi keagamaan dan keberagamaan yang berkembang di tengah-tengah kehidupan masyarakatnya. Desa Jepang yang memiliki tiga dusun Dusun Jepang, Pendem Kulon, dan Pendem Wetan adalah salah satu desa dengan tingkat tersendiri dalam kehidupan keberagamaan dan keagamaan masyarakatnya. Keunikan dari tingkat keagamaan dan keberagamaan masyarakat di Desa Jepang terlihat dari dinamika keagamaan dan keberagamaan yang berjalan dalam rutinitas kehidupan mereka bersama. Beberapa aktifitas kehidupan sosial yang berbasis budaya masyarakat masih banyak dijumpai di tengah-tengah kehidupan mereka. Misalnya, dapat diambil satu contoh budaya masyarakat yang masih tampak terlihat di tengah-tengah mereka adalah menyabung atau mengadu ayam.

Budaya menyabung ayam di tengah-tengah kehidupan masyarakat Jepang merupakan bagian dari fenomena sosial klasik kehidupan masyarakat yang berkembang. Tradisi yang dijalankan oleh masyarakat Desa Jepang ini disinyalir oleh sebagian masyarakat sebagai rutinitas kerja harian mereka yang bisa mengisi ruang-ruang kosong aktifitas kerja masyarakat. Tak ayal lagi, dari budaya sosial yang mereka miliki ini, masyarakat penuh keberanian untuk merawat ayam-ayam jago petarung dengan harga-harga yang sangat fantastis. Mulai dari harga lima puluh ribu rupiah sampai harga satu juta lima ratus ribu rupiah, mereka berani untuk tetap memiliki binatang peliharaan ini.

Sebuah keunikan lain yang bisa diamati dari kehidupan masyarakat Desa Jepang dengan budaya sosial yang berkembang di tengah-tengah kehidupan mereka adalah kesadaran keagamaan dan keberagamaan yang perlu mereka hadirkan dan upayakan eksis dalam kehidupan mereka sehari-hari. Agama bagi kehidupan mereka masih menduduki tingkat sekunder atau bahkan tingkat paling rendah dari realitas kehidupan keagamaan dan keberagamaan masyarakat. Masyarakat masih belum memiliki tingkat kesadaran keagamaan dan keberagamaan yang tinggi guna menjadikan ketertataan hidup mereka lebih baik. Dinamika dari kondisi ini sebenarnya dapat diamati dari struktur kehidupan masyarakat Desa Jepang yang masih tergolong pragmatik dalam pemenuhan struktur kehidupan mereka. Ekonomi menjadi basic need absolut dengan kesadaran perolehannya yang berhaluan positivistik. Secara otomatis pula, kondisi ini menggiring mereka untuk menomorduakan agama dari realitas kehidupan. Agama belum dihadirkan oleh mereka sebagai salah satu sebab yang bisa mendukung nilai keberhasilan dalam kehidupan sosial, ekonomi, dan kemasyarakatan.

Gambaran dari kondisi sosial yang muncul di tengah-tengah kehidupan masyarakat Desa Jepang sebagaimana telah dijelaskan di atas menjadi landasan utama Kegiatan Pengabdian Kepada Masyarakat di Desa Jepang Mejobo Kudus. Sebagai gambaran sederhana, Desa Jepang merupakan salah satu wilayah yang terdapat di Kecamatan Mejobo Kabupaten Kudus. Keberadaan desa ini merupakan salah satu desa yang bernaung di bawah Pemerintahan Kecamatan Mejobo selain Desa Payaman, Desa Mejobo, Desa Hadiwarno, Desa Golan Tepus, Desa Gulang, 
Desa Jojo, Desa Kesambi, Desa Kirig. Desa Mejobo, Desa Temulus, dan Desa Tenggeles. Mayoritas menerjuni pekerjaan di bidang pertanian. namun tidak sedikit penduduk Mejobo yang terjun sebagai wiraswasta di berbagai bidang usaha. Selain itu, Kecamatan Mejobo memiliki Dunia Usaha unggulan yang bergerak pada usaha kerajinan topi adat kudus, kerajinan anyaman, makanan, dan pandai besi ("Mejobo Kudus," n.d.).

Desa Jepang letak sebagian besar di dataran rendah, mempunyai luas wilayah $338,729 \mathrm{Ha}$ dengan luas lahan yang digunakan untuk sawah $89,324 \mathrm{Ha}$ (sawah irigasi semi teknis 13,614 Ha, tadah hujan 75,650 Ha dan lainnya 62,036 Ha), bukan sawah 249,405 Ha terdiri dari bangunan 151,290 Ha, jalan 3,700 Ha, lainnya $94.415 \mathrm{Ha}$. Suhu udara rata-rata 19 - 32 celcius, kelembaban udara 71,8\% - 87,9\%, curah hujan $1459 \mathrm{~mm} /$ th, tinggi tempat 14 MDL ("Profil Desa Jepang," n.d.).

Pada bagian kewilayahan, Desa Jepang berbatasan dengan beberapa desa di sekitarnya. Sebelah Barat desa berbatasan dengan Desa Jepang Pakis Kecamatan Jati, sebelah Timur desa berbatasan dengan Desa Mejobo Kecamatan Mejobo, sebelah Utara desa berbatasan dengan Desa Megawon Kecamatan Jati, dan sebelah sebelah Selatan desa berbatasan dengan Desa Gulang atau Desa Payaman Kecamatan Mejobo. Adapun jarak tempuh Desa Jepang ke kecamatan adalah 1,8 km, sementara jarak tempuh ke kabupaten adalah $6 \mathrm{~km}$. Letak pemerintahan Desa Jepang yang berdekatan dengan pusat pemerintahan kecamatan menjadikan desa ini strategis dalam lintasan wilayah desa ("Profil Desa Jepang," n.d.).

\section{Fenomena Keagamaan Masyarakat Desa Jepang Mejobo Kudus}

Berpijak kepada beberapa analisis mendasar dari eksplorasi tentang latar belakang lokasi dan struktur sosial keberagamaan yang terdapat di Desa Jepang Mejobo Kudus di atas, tampak Desa Jepang sebagai wilayah yang berdekatan dengan pusat administrasi Kecamatan Mejobo. Letak wilayah yang cukup strategis ini menjadikan Desa Jepang Mejobo Kudus sebagai salah satu desa yang menjadi perlintasan lalu lintas masyarakat ke Desa Mejobo, Desa Kirig, Desa Kesambi, Desa Jojo, Desa Bulung, dan jalur perlintasan alternatif ke Kota Pati melewati Desa Gadu dan juga ke Kota Purwodadi melewati Desa Sukolilo. Perlintasan yang sangat strategis ini menjadikan Desa Jepang tersorot aktivitas sosial kemasyarakatannya, mulai ekonomi, politik, agama, dan kebudayaan yang berjalan. Desa Jepang Mejobo Kudus secara otomatis menjadi tersorot aktivitas sosial kemasyarakatan dan keagamaannya di antara setiap orang yang singgah melewati desa ini.

Menyoroti dimensi keagamaan dan keberagamaan masyarakat Desa Jepang, desa ini cenderung unik untuk dipersepsikan nilai-nilai keagamaan dan keberagamaan masyarakatnya. Keunikan tersebut tampak dari kehidupan masyarakatnya yang masih terlihat abangan dalam progresifitas Kota Kudus yang disinyalir sebagai Kota Santri. Fenomena ini tentu tidak jauh berbeda dengan mayoritas masyarakat Jawa yang pada prinsip keagamaannya cenderung menjadi penganut daripada pemeluk agama, dalam hal ini agama Islam. Bambang Pranowo 
(2011, hal. 7) atas kutipannya pada penjelasan Koentjaraningrat menjelaskan ketika masyarakat Jawa ditanya tentang keberagamaannya, sebagian besar dari mereka akan menjawab bahwa dirinya penganut Agami Islam (agama Islam). Hal ini lebih lanjut juga dicatat oleh Bambang Pranowo bahwa lebih dari 95 persen dari kurang lebih 55 juta orang Jawa adalah muslim. Meskipun, menurut Ricklefs, masyarakat Jawa kadang-kadang dianggap muslim yang buruk, namun dalam pandangan Ricklefs, pernyataan ini tidak akan membantu seorang pengkaji atas masyarakat Jawa dalam memahami bagaimana perkembangan agama di Jawa, apa saja alasan keunikannya, atau di mana posisinya dalam sejarah Islam atau agama secara umum.

Secara sederhana dan dalam pandangan umum, beragama adalah kepercayaan dan perbuatan yang berkaitan dengan hubungan manusia dengan kekuatan atau wujud gaib (relationship between humans and supernatural forces or beings). Dengan demikian, ada hal-hal yang alamiah atau natural dan ada pula yang supernatural. Yang natural, alamiah atau biasa dikenal orang sebagai bagian dari kehidupan beragama. Agama adalah yang berhubungan dengan yang supernatural, yang luar biasa, atau yang gaib. Namun, batas antara apa yang gaib dan nyata, yang supernatural dan yang natural sangat kabur dan relatif (Agus, 2006, hal. 46). Kenyataan ini pula yang menjadikan hipotesis Bambang Pranowo di atas bahwa masyarakat Jawa mayoritas adalah penganut Agami Islam (Penganut Agama Islam) sebagai argumentasi yang cukup relevan bagi kehidupan masyarakat di Desa Jepang Mejobo Kudus.

Mengamati realitas keagamaan masyarakat Desa Jepang Mejobo Kudus, memangakan dipertemukan dengan dinamikakehidupan masyarakatnya yang sangat majemuk. Sebagai alasannya, titik relevansi penganut Agami Islami sebagaimana dipersepsikan pada beberapa masyarakat Jawa juga tidak berlaku pada mayoritas masyarakat Desa Jepang. Hal ini sebagaimana Mas'udi (2012) mendeskripsikan struktur kehidupan masyarakat Desa Jepang menjadi tiga bentuk, kyai, santri, dan masyarakat biasa. Tiga bentuk struktur sosial ini tentunya tidak jauh berbeda dari hipotesis Geertz atas masyarakat Jawa yang mengklasifikasikannya menjadi tiga varian, abangan, santri, dan priyayi.

Geertz dalam Religion of Java sebagaimana dijelaskan oleh Bambang Pranowo menyebutkan bahwa identitas muslim Jawa dengan merumuskan trikotomi abangan, santri, dan priyayi. Menurut Geertz, tradisi agama abangan, yang dominan dalam masyarakat petani, terutama terdiri dari ritual-ritual yang dinamai slametan, kepercayaan yang kompleks dan rumit terhadap roh-roh, dan teori-teori serta praktik-praktik pengobatan tenung dan sihir. Slametan, sebagai ritual terpenting masyarakat abangan, bertujuan menenangkan roh-roh dan untuk memperoleh keadaan slamet-yang ditandai dengan tidak adanya perasaan sakit hati pada orang lain serta keseimbangan emosional. Di lain pihak, kelompok santri diasosiasikan dengan Islam yang murni. Mereka berpengaruh khususnya di kalangan pedagang Jawa serta petani-petani Jawa yang relatif kaya. Ciri tradisi beragama kaum santri adalah pelaksanaan ajaran dan perintah-perintah dasar agama Islam secara hatihati, teratur, dan juga oleh organisasi sosial dan amal, serta Islam politik yang begitu kompleks (Pranowo, 2011, hal. 8). 
Klasifikasi terstruktur yang dimunculkan oleh Geertz terhadap realitas kehidupan masyarakat Jawa di atas, tentu pada dataran yang universal banyak menuai kritik dan persoalan. Hal ini tentunya disandarkan kepada dinamikan umum kehidupan masyarakat Jawa yang cenderung melebur di antara satu varian dengan varian lain. Santri dalam kebudayaan yang dijalankannya juga menikmati budaya kaum abangan. Kaum priyayi dalam kehidupannya juga dimungkinkan berkolaborasi dengan budaya kaum santri karena mereka juga harus berkecimpung intensif bersama mereka.

Menjejak pada kemungkinan antitesis atas tesis Geertz pada struktur kebudayaan dan struktur agama masyarakat Jawa, Bambang Pranowo mengetengahkan adanya dua dimensi universal yang berjalan di kehidupan masyarakat Jawa. Bambang Pranowo mencatat konsep tradisi besar dan tradisi kecil yang diperkenalkan oleh Roert Redfield. Pasangan konsep ini kemudian bayak digunakan dalam studi-studi tentang masyarakat Afrika, Asia, dan Amerika Latin. Ketika memperkenalkan konsep tradisi besar dan tradisikecil, Redfield menyatakan, "Dalam sebuah peradaban terdapat tradisi besar sejumlah kecil orang-orang reflektif, dan juga terdapat tradisi kecil sekian sekian banyak orang-orang yang tidak reflektif. Tradisi besar diolah dan dikembangkan di sekolah-sekolah atau kuil-kuil (candi); tradisikecil berjalan dan bertahan dalam kehidupan kalangan tak berpendidikan dalam masyarakat-masyarakat desa. Tradisi filsuf, teolog, dan sastrawan adalah tradisi yang dikembangkan dan diwariskan secara sadar; sementara tradisi orangorang kecil sebagian besar adalah hal-hal yang diterima apa adanya (taken for granted) dan tidak pernah diselidiki secara kritis ataupun dianggap patut diperbaiki dan diperbaharui" (Pranowo, 2011, hal. 13).

\section{Simpulan}

Kehidupan masyarakat Desa Jepang Mejobo Kudus dalam perjalanannya mengalami fase-fase yang sangat dinamis. Dinamika ini muncul seiring dengan kekuatan kebudayaan dan agama yang berjalan di tengah-tengah mereka senantiasa berpacu dengan kenyataan waktu yang mengitari. Di antara kondisi klasik masyarakat yang cenderung dianggap awam, namun pada perjalanannya kekinian, mereka melestarikan budaya sambil meneguhkan semangat beragama. Semangat ini tampak dengan jelas dengan semakin meningginya intensitas mereka untuk menghadiri, majlis-majlis pengajian dan mengisi tempat-tempat ibadah secara masif dan berkelanjutan. 


\section{Referensi}

Agus, B. (2006). Agama dalam Kehidupan Manusia (Prngantar Antropologi Agama). Jakarta: RajaGrafindo Persada.

Martin, R. C. (2011). Pendekatan Kajian Islam dalam Studi Agama. Surakarta: Muhammadiyah University Press.

Mas'ud, A. (2004). Antologi Studi Agama dan Pendidikan. Semarang: Aneka Ilmu.

Mas'udi. (2012). Genealogi Petilasan Sunan Kudus (Sejarah Masjid Wali dalam Dakwah Sunan Kudus di Desa Jepang Mejobo Kudus. STAIN Kudus, Kudus.

Mejobo Kudus. (n.d.). Diambil dari http://id.wikipedia.org/wiki/Mejobo,Kudus

Permata, A. N. (2000). Metodologi Studi Agama. Yogyakarta: Pustaka Pelajar.

Pranowo, B. (2011). Memahami Islam Jawa. Jakarta: Pustaka Alvabet.

Profil Desa Jepang. (n.d.). Diambil dari http://mejobo.kuduskab.go.id/desaa.php\#

Abdurrahaman Masud, Antologi Studi Agama dan Pendidikan. Semarang: Aneka Ilmu, 2004.

Agus Yusrun Nafi', Kearifan Rebo Wekasan, dalam http://suaramerdeka.com/v1/ index.php/read/cetak/2012/02/03/175875/Kearifan-Rebo-Wekasan, diakses, tanggal, 5 Mei 2012.

Ahmad Norma Permata, (ed.), Metodologi Studi Agama. Yogyakarta: Pustaka Pelajar, 2000.

Ali Abdul Wahid Wafi, Al-Musaawaatu fi al-Islam" Mesir: Dar Ma’arif Mesir, ttt.

Departemen Pendidikan Nasional, Kamus Besar Bahasa Indonesia. Jakarta: Gramedia, 2008.

Format Laporan, Profil Desa dan Kelurahan Tahun 2011, Desa Jepang Kecamatan Mejobo Kabupaten Kudus.

Mark R Woodward, Islam Jawa (Kesalehan Normatifversus Kebatinan), terj., Hairus Salim HS (Yogyakarta: LKiS, 1999), hlm. 29.

Mas'udi, "Genealogi Petilasan Sunan Kudus (Sejarah Masjid Wali dalam Dakwah Sunan Kudus di Desa Jepang Mejobo Kudus)" dalam Laporan Penelitian, STAIN Kudus, 2012.

Mejobo Kudus dalam http://id.wikipedia.org/wiki/Mejobo,Kudus. Diakses tanggal, 17 Juli 2012.

Pranowo, Bambang. Memahami Islam Jawa. Jakarta: Pustaka Alvabet, 2011.

Profil Desa Jepang, http://mejobo.kuduskab.go.id/desaa.php\# diunduh tanggal, 17 
Juli 2012.

Richard C. Martin, Pendekatan Kajian Islam dalam Studi Agama, terj., Zakiyuddin Baidhawy. Surakarta: Muhammadiyah University Press, 2001.

Wawancara dengan Bapak Bejo di daerah pembakaran batu bata tepatnya daerah Pendem Wetan, tanggal, 15 Juli 2012, jam 09.00.

Wawancara dengan Bapak Indarto, Kepala Desa Jepang, tanggal 16 Juli 2012, jam 19.15-22.00.

Wawancara dengan Bapak Sumaji di daerah pembakaran batu bata tepatnya di Dukuh Pendem Wetan, tanggal, 15 Juni 2012, jam 09.00-10.00. Adapun Bapak Suwaji sendiri merupakan generasi penerus dari pembuatan batu bata. Umur Bapak Suwaji saat ini sudah mencapai 60 tahun. 
Masu'di 
Masu'di 
Masu'di 